See discussions, stats, and author profiles for this publication at: https://www.researchgate.net/publication/355038596

\title{
Curiosity Helps: Growth In Need for Cognition Bidirectionally Predicts Future Reduction In Anxiety and Depression Symptoms Across 10 Years
}

Article in Journal of Affective Disorders · October 2021

DOI: 10.1016/j.jad.2021.10.001

CITATIONS

READS

0

43

2 authors:

(8) Nur Hani Zainal

Harvard Medical School - Massachusetts General Hospital

39 PUBLICATIONS 391 CITATIONS

SEE PROFILE

Michelle Gayle Newman

Pennsylvania State University

259 PUBLICATIONS 8,334 CITATIONS

SEE PROFILE

Some of the authors of this publication are also working on these related projects:

Project ISEE stimuli project View project

Multimodal connectome analysis for differentiating subtypes within early-stage dementia and mild cognitive impairment View project 
Please cite as: Zainal, N. H. \& Newman, M. G. (in press). Curiosity helps: Growth in need for cognition bidirectionally predicts future reduction in anxiety and depression symptoms across 10 years. Journal of Affective Disorders. doi: https://doi.org/10.1016/j.jad.2021.10.001

Curiosity Helps: Growth In Need for Cognition Bidirectionally Predicts Future Reduction In Anxiety and Depression Symptoms Across 10 Years

\author{
Nur Hani Zainal, M.S. ${ }^{1}$ \\ Harvard Medical School - Massachusetts General Hospital \\ The Pennsylvania State University \\ National University of Singapore
}

Michelle G. Newman, Ph.D.

The Pennsylvania State University

Word count: $\quad 4,500$

Number of tables: 2

Number of figures: 2

${ }^{1}$ To whom all correspondence should be directed: nvz5057@psu.edu. 


\section{Corresponding Author:}

Nur Hani Zainal, M.S.

Clinical Fellow in Psychology, Harvard Medical School - Massachusetts General Hospital

Ph.D. Candidate, The Pennsylvania State University

Senior Tutor, National University of Singapore

Phone: 917-767-7088

E-mail:nzainal@mgh.harvard.edu

\section{Co-Author:}

Michelle G. Newman, Ph.D.

Professor of Psychology and Psychiatry

Editor, Behavior Therapy

Fellow, Association for Behavioral and Cognitive Therapies

Fellow, American Psychological Association Divisions 12 and 29

Director of the Laboratory for Anxiety and Depression Research

Department of Psychology

371 Moore Building

The Pennsylvania State University

University Park, PA 16802-3103

Phone: 814-863-1148

Email: mgn1@psu.edu

Fax: 814-863-7002

\section{Data Availability Statement}

The data used in this publication were made available upon request by the CentERdata, Tilburg University, PO Box 90153, 5000 LE Tilburg, The Netherlands via correspondence with Gamze Demirel and instructions listed on the data repository website (https://www.lissdata.nl/node/27).

\section{Conflict of Interest Statement}

Both authors do not have any conflicts of interest.

\section{Funding Sources}

The Longitudinal Internet Survey Study (LISS) has been funded by the following grants and agencies: Dutch Research Counsel (NWO); Fonds Slachtofferhulp, The Haque, The Netherlands (50006/VICTIMS). The original investigators and funding agency are not responsible for the analyses or interpretations presented here.

\section{Acknowledgements}

All authors have (1) made substantial contributions to analysis and interpretation of the study and its findings; (2) drafted and revised the article for intellectual content; and (3) gave their final 
approval of the version to be submitted. The manuscript has been read and approved by all authors. I was involved in the conceptualization, formal analysis, coding with the R software for the data analysis, visualization, and writing (original draft, reviewing, editing) of this work. Dr. Newman assisted with the data curation, validation, supervision, and writing (original draft, reviewing, editing) of the manuscript. 


\section{Highlights}

- Lower level of need for cognition (NFC) predicted higher future anxiety and depression symptoms (ADS).

- Likewise, within-person larger reduction in NFC forecasted greater future increase in ADS.

- Within-person relations held after adjusting for between-person effects, regression to the mean, baseline scores, and socio-demographic variables.

- Between persons, lower NFC correlated with higher ADS across all time-points.

- All within-person causal and between-person correlational effect sizes ranged from moderate-to-large. 


\begin{abstract}
Introduction: Decreased motivational tendency to seek out, engage in, and enjoy investing in complex cognitive processes in a sustained manner (need for cognition; NFC) may be a predictor and consequence of heightened anxiety and depression symptoms (ADS). However, the majority of investigations on this topic have been cross-sectional, which hinders causal inferences. Methods: The current study thus determined the within-person relations between NFC and ADS by using random intercept cross-lagged panel model (RI-CLPM) and bivariate dual latent change score (BLCS) approaches to separate between- and within-person effects. RI-CLPM and BLCS also present with advantages of adjusting for regression to the mean, baseline scores, autoregressive and lagged effects, and minimizing measurement error. Community-dwelling adults $(n=6750)$ completed the Mental Health Inventory-5 and trait-level NFC scales approximately every one year across 10 years. Results: RI-CLPM showed that within persons, lower level of NFC predicted higher future level of ADS, and vice versa $(d=-$ 0.852 to -0.498$)$. Likewise, BLCS demonstrated that within persons, smaller change in NFC forecasted larger subsequent increase in ADS, and conversely $(d=-0.631$ to -0.519$)$. Findings remained after adjusting for socio-demographic covariates. Conclusion: Consistent with theories, findings suggested that the within-person level-to-future level and change-to-future change relations among NFC and ADS were bi-directional and negative, with moderate-to-large effect sizes. Targeting NFC may treat or prevent the emergence of depression and anxiety disorders. Such efforts may include augmenting or personalizing evidence-based cognitive behavioral therapeutic strategies for individuals with or at-risk for heightened ADS. Keywords: need for cognition; depression; anxiety; random-intercept cross-lagged panel model; latent change
\end{abstract}


Word count: 247 


\section{Figure 1}

Random-intercepts cross-lagged panel model of MHI and NFC across 10 time-points

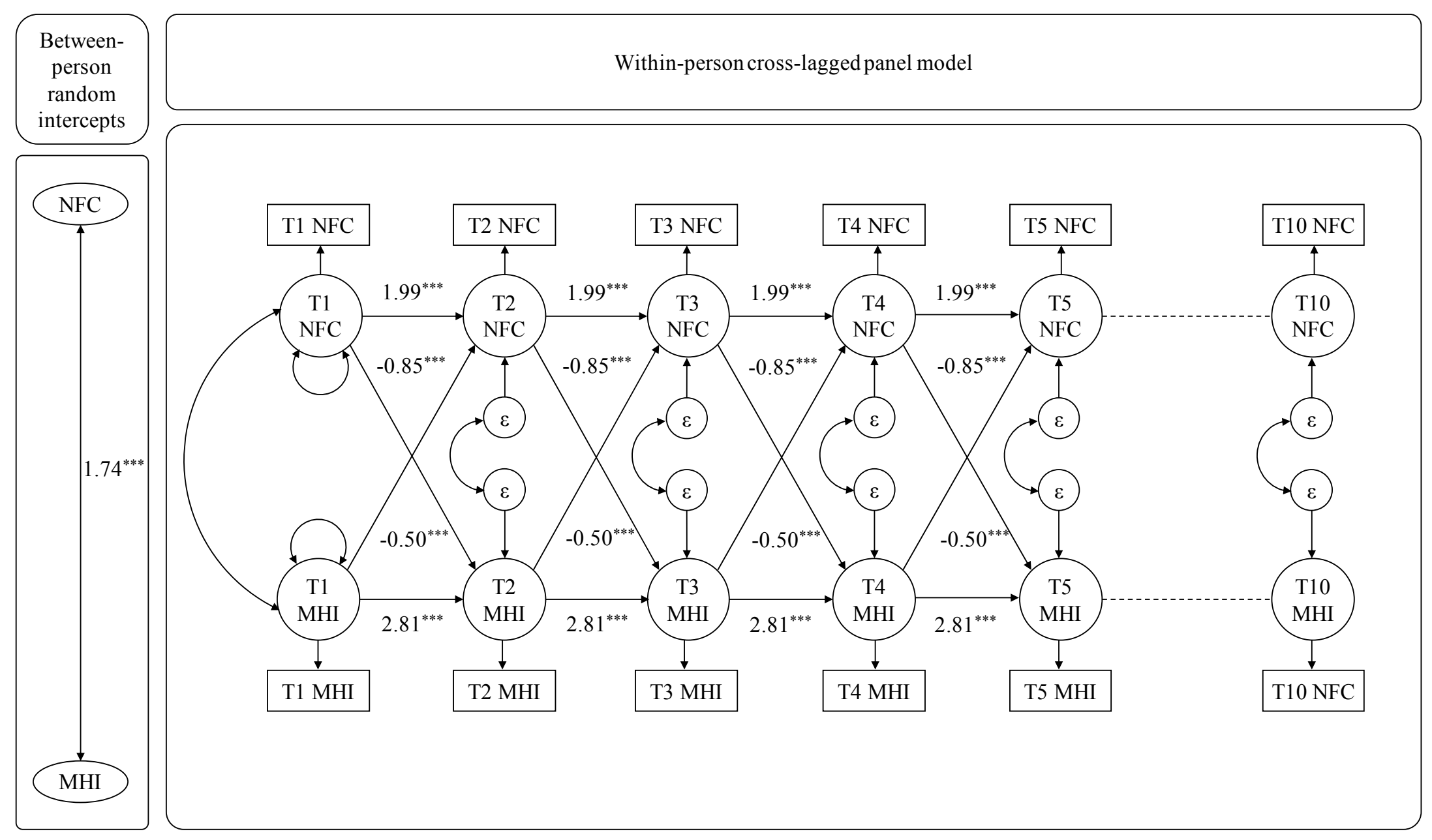

Note. ${ }^{* * *} p<.001$. 
$\mathrm{MHI}=$ mental health symptom severity; NFC = need for cognition; Cohen's $d$ parameter estimates were displayed. Within-person cross-lagged effects refer to level in MHI at a prior time-point (T-1) predicting $(\rightarrow)$ future $\Delta$ in NFC at the next adjacent time-point (T) (and vice versa). Each unique within-person coupling effects and proportional effects, residual covariances between MHI and NFC, as well as variances of MHI and NFC were fixed to be equal across all 9 time-lags. A subset of the 10 time-points were shown due to space constraints. 
Figure 2

Bivariate dual latent change score model of MHI and NFC across 10 time-points

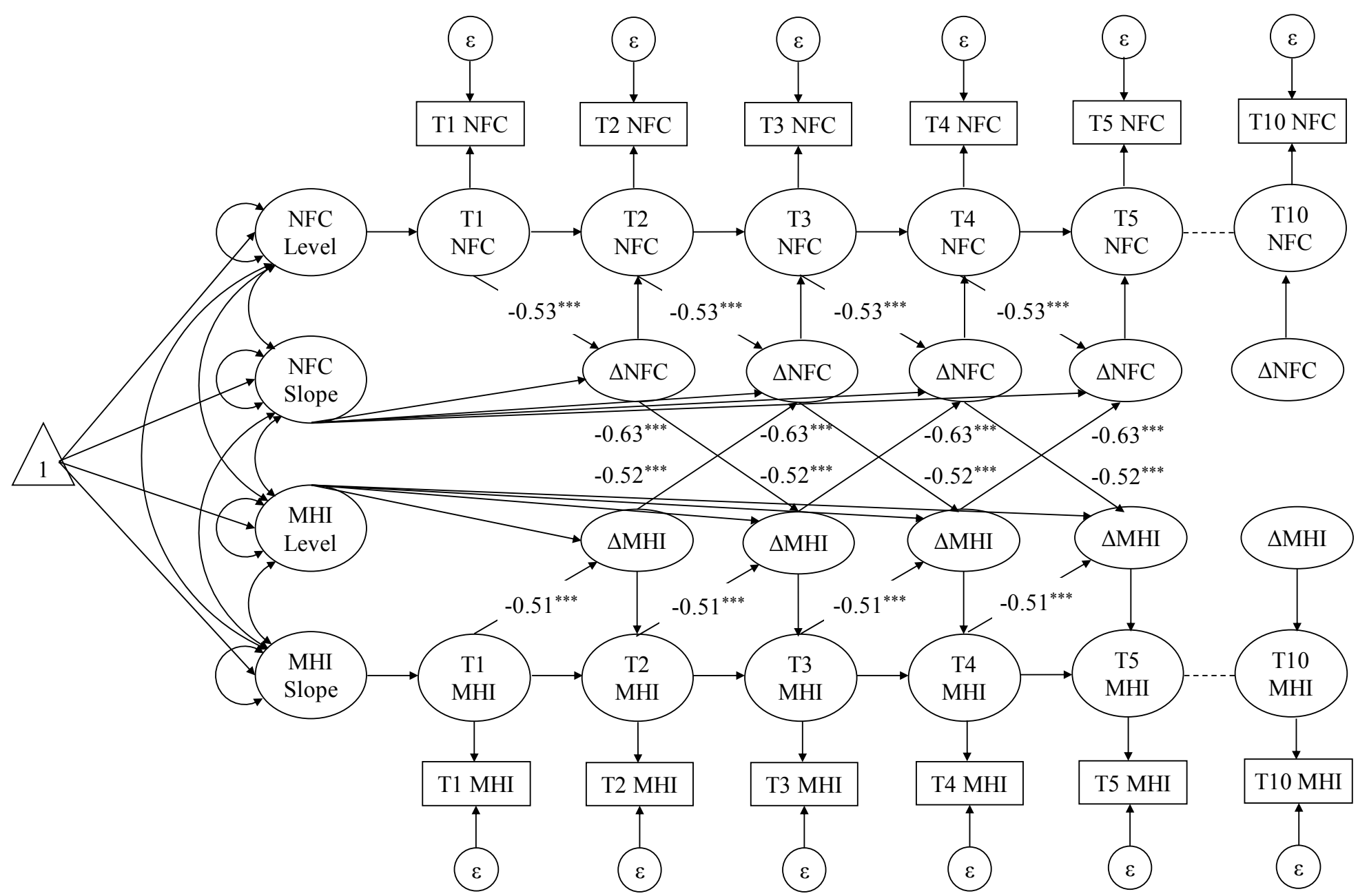

Note. ${ }^{* * *} p<.001$. 
$\mathrm{MHI}=$ mental health symptom severity; NFC = need for cognition. Cohen's $d$ parameter estimates were displayed. Within-person coupling effects refer to change $(\Delta)$ in MHI at a prior time-lag $(\Delta \mathrm{T}-1)$ predicting $(\rightarrow)$ future $\Delta$ in NFC at the next adjacent time-lag $(\Delta \mathrm{T}$; and vice versa). Each unique within-person coupling effects and proportional effects, residual covariances between MHI and NFC, as well as variances of MHI and NFC were fixed to be equal across all 9 time-lags. 
Table 1

Random-intercepts cross-lagged panel model of ADS and NFC across 10 time-points

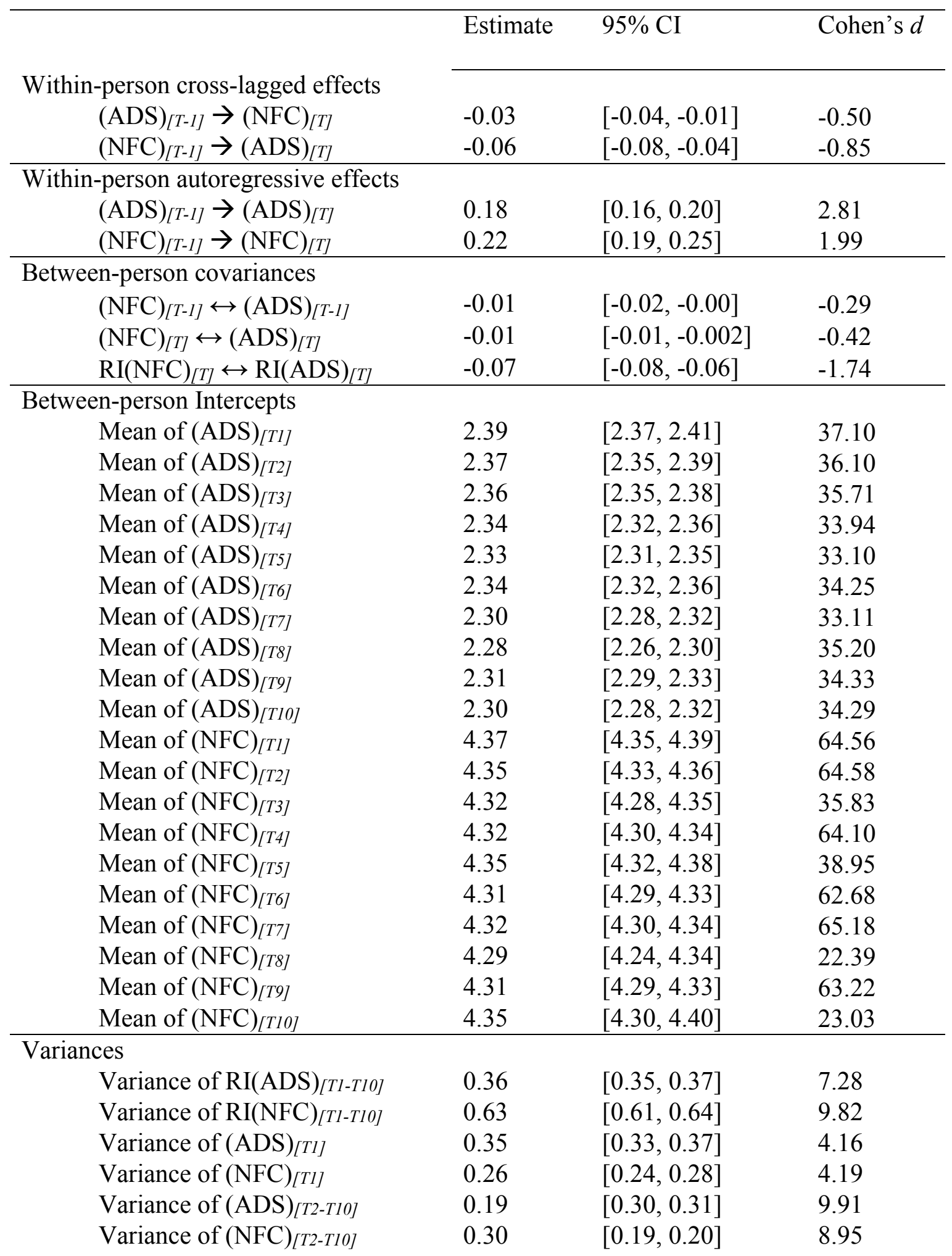


Note. $\mathrm{CI}=$ confidence interval; $\mathrm{ADS}=$ anxiety and depression symptoms; $\mathrm{NFC}=$ need for cognition; RI = random intercept.

Model fit indices: $\chi^{2}(d f=197)=773.72, \mathrm{CFI}=.986, \mathrm{RMSEA}=.016, \mathrm{SRMR}=.037$. Withinperson cross-lagged effects refer to level in ADS at a prior time-point (T-1) predicting $(\rightarrow)$ future $\Delta$ in NFC at the next adjacent time-point (T) (and vice versa). Within-person coupling effects and proportional effects, residual covariances between ADS and NFC, as well as variances of ADS and NFC were each uniquely fixed to be equal across all 9 time-lags. 
Table 2

Bivariate dual latent change score model of ADS and NFC across 10 time-points

\begin{tabular}{|c|c|c|c|}
\hline & Estimate & $95 \% \mathrm{CI}$ & Cohen's $d$ \\
\hline \multicolumn{4}{|l|}{ Within-person coupling effects } \\
\hline$\Delta(\mathrm{ADS})_{[\Delta T-1]} \rightarrow \Delta(\mathrm{NFC})_{[\Delta T]}$ & -0.51 & {$[-0.77,-0.24]$} & -0.52 \\
\hline$\Delta(\mathrm{NFC})_{[\Delta T-1]} \rightarrow \Delta\left(\mathrm{ADS}_{[\Delta T]}\right.$ & -0.89 & {$[-1.28,-0.51]$} & -0.63 \\
\hline \multicolumn{4}{|l|}{ Within-person proportional effects } \\
\hline$\Delta(\mathrm{ADS})_{[\Delta T-1]} \rightarrow \Delta(\mathrm{ADS})_{[\Delta T]}$ & -0.10 & {$[-0.15,-0.05]$} & -0.51 \\
\hline$\Delta(\mathrm{NFC})_{[\Delta T-1]} \rightarrow \Delta(\mathrm{NFC})_{[\Delta T]}$ & -0.13 & {$[-0.19,-0.06]$} & -0.53 \\
\hline \multicolumn{4}{|l|}{ Between-person covariances } \\
\hline$(\mathrm{ADS})_{[T-1]} \leftrightarrow \Delta(\mathrm{ADS})_{[\Delta T]}$ & 0.02 & {$[0.01,0.04]$} & 0.34 \\
\hline$(\mathrm{NFC})_{[T-1]} \leftrightarrow \Delta(\mathrm{NFC})_{[\Delta T]}$ & 0.07 & {$[0.03,0.11]$} & 0.46 \\
\hline$(\mathrm{NFC})_{[T-1]} \leftrightarrow \Delta(\mathrm{ADS})_{[T-1]}$ & -0.08 & {$[-0.10,-0.06]$} & -1.35 \\
\hline$(\mathrm{NFC})_{[\Delta T]} \leftrightarrow \Delta(\mathrm{ADS})_{[\Delta T]}$ & 0.003 & {$[0.002,0.004]$} & 0.70 \\
\hline$(\mathrm{ADS})_{[T-1]} \leftrightarrow \Delta(\mathrm{NFC})_{[\Delta T]}$ & -0.02 & {$[-0.02,-0.01]$} & -0.55 \\
\hline$(\mathrm{NFC})_{[T-1]} \leftrightarrow \Delta(\mathrm{ADS})_{[\Delta T]}$ & -0.02 & {$[-0.02,-0.01]$} & -0.59 \\
\hline$(\mathrm{NFC})_{[T]} \leftrightarrow \Delta(\mathrm{ADS})_{[T]}$ & -0.002 & {$[-0.01,0.001]$} & -0.18 \\
\hline \multicolumn{4}{|l|}{ Between-person Intercepts } \\
\hline Mean of $(\mathrm{ADS})_{[T 1]}$ & 2.38 & {$[2.37,2.40]$} & 39.26 \\
\hline Mean of $\Delta(\mathrm{ADS})_{[T]}$ & 0.21 & {$[0.09,0.32]$} & 0.48 \\
\hline Mean of $(\mathrm{NFC})_{[T 1]}$ & 4.36 & {$[4.34,4.37]$} & 66.60 \\
\hline Mean of $\Delta(\mathrm{NFC})_{[T]}$ & 0.54 & {$[0.26,0.82]$} & 0.52 \\
\hline \multicolumn{4}{|l|}{ Variances } \\
\hline Variance of $(\mathrm{ADS})_{[T 1]}$ & 0.41 & {$[0.39,0.43]$} & 5.40 \\
\hline Residuals of $\Delta(\mathrm{ADS})_{[T]}$ & 0.27 & {$[0.27,0.28]$} & 10.10 \\
\hline Variance of $\Delta(\mathrm{ADS})_{[T]}$ & 0.10 & {$[0.004,0.01]$} & 0.49 \\
\hline Variance of $(\mathrm{NFC})_{[T 1]}$ & 0.68 & {$[0.65,0.70]$} & 7.96 \\
\hline Residuals of $\Delta(\mathrm{NFC})_{[T]}$ & 0.18 & {$[0.17,0.18]$} & 8.74 \\
\hline Variance of $\Delta(\mathrm{NFC})_{[T]}$ & 0.01 & {$[0.003,0.03]$} & 0.35 \\
\hline
\end{tabular}

$\overline{\text { Note } .} \mathrm{CI}=$ confidence interval; $\mathrm{ADS}=$ anxiety and depression symptoms; $\mathrm{NFC}=$ need for cognition.

Model fit indices: $\chi^{2}(d f=209)=795.68, \mathrm{CFI}=.986, \mathrm{RMSEA}=.016$, SRMR $=.038$. Withinperson coupling effects refer to change $(\Delta)$ in ADS at a prior time-lag $(\Delta \mathrm{T}-1)$ predicting $(\rightarrow)$ future $\Delta$ in NFC at the next adjacent time-lag ( $\Delta \mathrm{T}$; and vice versa). Within-person coupling effects and proportional effects, residual covariances between ADS and NFC, as well as variances of ADS and NFC were each uniquely fixed to be equal across all 9 time-lags. 
Curiosity Helps: Growth In Need for Cognition Bidirectionally Predicts Future Reduction In Anxiety and Depression Symptoms Across 10 Years

The power to question is the basis of all human progress.

- $\quad$ Indira Gandhi (Patel, 2017)

Elevated anxiety and depression symptoms (ADS) are commonly observed in the general population (Haller, Cramer, Lauche, Gass, \& Dobos, 2014; Petty, Brinol, Loersch, \& McCaslin, 2009; Rodríguez, Nuevo, Chatterji, \& Ayuso-Mateos, 2012). Such widespread ADS has been reliably connected with decreased life satisfaction, poor academic functioning, stunted career development, high relationship distress, and diverse health problems (Bertha \& Balázs, 2013; Curran, Rosato, Ferry, \& Leavey, 2020). Various health issues include autoimmune, cardiovascular, musculoskeletal, and neurocognitive medical diseases that could run a chronic course and hamper daily functioning (Deschênes, Burns, \& Schmitz, 2018; Rzewuska, Mallen, Strauss, Belcher, \& Peat, 2015; Zainal \& Newman, 2021c, 2021b; Zainal \& Newman, in press-b, 2018; Zainal \& Newman, in press-a). Collectively, elevated depression and anxiety burden society and limit economic growth via reduced rate and productivity in the workforce, greater work absenteeism and sickness presenteeism (Skagen \& Collins, 2016), and increased government spending on healthcare and welfare systems (Schofield et al., 2011). Thus, identifying and enhancing understanding of the correlates, predictors, and outcomes of heightened ADS are essential.

Need for cognition (NFC) presents as a potential concurrent and prospective predictor of increased ADS. Originally coined by Cohen, Stotland, and Wolfe (1955), NFC is defined as the yearning to comprehend and make meaning or structure of the world and relevant circumstances in cogent ways. Building off this definition, during the past few decades, NFC has often been 
conceptualized as a personality trait reflecting the predilection to immerse in, contemplate on, and derive pleasure from mentally engaging in various complex topics or problems with sustained intrinsic motivation, effort, and enjoyment (Cacioppo \& Petty, 1982; Cacioppo, Petty, Kao, \& Rodriguez, 1986; Thompson, Chaiken, \& Hazlewood, 1993). Critically, NFC is believed to indicate a dispositional cognitive motivation that relates to intelligence and other cognitive capacities. This idea has been supported consistently by research showing that trait NFC had small but significant correlations with some cognitive capacity scores (Gauthier, Christopher, Walter, Mourad, \& Marek, 2006; Hill, Foster, Sofko, Elliott, \& Shelton, 2016), such as higher general, fluid, and crystalized intelligence (Hill et al., 2013), as well as giftedness, and markers of academic achievement (e.g., examination grades; Luong et al., 2017; Meier, Vogl, \& Preckel, 2014). However, NFC has been shown to have zero or weak relations with rudimentary executive functioning domains, such as inhibitory control and working memory (Gartner et al., 2021). Beyond intellectual abilities, NFC concurs with individuals' propensity to expend their cognitive resources (von Stumm \& Ackerman, 2013). NFC has been found to be significantly correlated with the Big 5 (Fleischhauer et al., 2010). In particular, it was most strongly correlated with openness to experience $(r=.41)$, but displayed weaker relations with other Big 5 personality traits of neuroticism $(r=-.26)$, conscientiousness $(r=.25)$, agreeableness $(r=.17)$, and extraversion $(r=.22)$ (Fleischhauer et al., 2010).

Persons with reduced motivation to actively and systematically seek out, consider, and think about corrective information (i.e., low NFC) have been posited to be susceptible to experiencing low mood or elevated ADS across long durations (Cacioppo, Petty, Feinstein, \& Jarvis, 1996). Such low NFC can hinder the generation of positive and helpful thoughts over time. Moreover, it has been thought that persons low in NFC are less likely to seek and process 
information adaptively and thus to develop a sense of heightened psychological well-being across time in part due to chronic discomfort with uncertain, stressful, and ambiguous situations (Iannello, Mottini, Tirelli, Riva, \& Antonietti, 2017; Lachlan, Hutter, Gilbert, \& Spence, 2021). Further, theorists have proposed that persons with lower trait NFC are less likely to habitually examine biases, use critical thinking (West, Toplak, \& Stanovich, 2008), and adopt healthy lifestyles, mindsets, or action repertoires that would bring forth personal and professional growth circumstances over the course of life (Petty et al., 2009). Such factors can thereby place them at risk for future increased ADS. In addition, based on the literature (Feist, 2012; Hill \& Aita, 2018; Sandra \& Otto, 2018), it is plausible that reduced NFC might be a risk factor for subsequent ADS as it has been related to decreased goal persistence and adaptive mindsets in the face of challenging yet potentially rewarding tasks and experiences.

Thus far, seven studies have investigated the cross-sectional associations between NFC and mental health-related constructs. Lower NFC was related with higher depression severity (Reeves, Watson, Ramsey, \& Morris, 1995), trait negative affect, affective instability (Fleischhauer et al., 2010), tendency to put things off, and difficulties meeting deadlines (Zhou, 2019) among undergraduates. Relatedly, college students and community-dwelling adults with less NFC displayed reduced life satisfaction (Gauthier et al., 2006). Similarly, MTurk workers with decreased NFC had greater math anxiety and engaged in fewer meta-cognitive activities (Maloney \& Retanal, 2020). In addition, Chinese community adults with lower NFC showed higher odds of addictive behaviors, such as excessive, nonconstructive, and problematic Internet use (Shi, Chen, \& Tian, 2010). Also, reduced NFC was correlated with higher anxiety about learning unfamiliar foreign languages among Iranian college students (Rezazadeh \& Zarrinabadi, 2020). However, these single-time-point studies do not offer information about the directionality 
of the relations between NFC and ADS constructs due to the absence of temporal precedence (Blackwell \& Glynn, 2018). Longitudinal studies that establish temporal precedence in addition to covariation are thus needed to move us closer to understanding causal relations (Granger, 1969; Pearl, 2009) between NFC and ADS.

To date, four prospective studies have examined the associations between NFC and constructs pertinent to mental health. For instance, Gallagher (2012) observed that lower NFC predicted more irritability and depressed mood as well as reduced motivation and feeling of being useful at the workplace a month later. Relatedly, in mid-life and older community adult retirees, lower NFC dovetailed with greater depression symptoms after a year (Baer et al., 2013). Similarly, decreased NFC preceded and related to higher depression symptoms following four weeks among Japanese college students (Nishiguchi, Takano, \& Tanno, 2016). Moreover, within persons, lower NFC was associated with less creative thinking skills a year later among Chinese high school students with adequate perceived peer support (Chen \& Zhang, 2020); however, directionality was not determined in that study.

Simultaneously, it is plausible that elevated mental health severity could relate to subsequent reduced NFC. This is because persons with heightened ADS have been theorized to be inclined to repeatedly avoid expending mental effort to gather and evaluate facts as part of optimal problem solving and decision-making processes (Dalgleish \& Werner-Seidler, 2014; Patzelt, Kool, Millner, \& Gershman, 2019). Moreover, elevated ADS can compromise analytical thinking, goal-directed pursuits, and reality testing skills (Culbreth, Westbrook, \& Barch, 2016; Tomljenovic \& Bubic, 2019; Zainal \& Newman, 2019), as well as increase vulnerability to cognitive distortions (e.g., jumping to conclusions, black-and-white thinking) over long durations (Barron et al., 2018). Thus, based on this scar theory (Allemand, Grünenfelder-Steiger, \& 
Flückiger, 2018; Schmidt, Lerew, \& Joiner, 2000), increased ADS would likely relate to lower trait NFC across time.

To our knowledge, only two longitudinal studies have examined if mental health-related constructs was associated with subsequent NFC. A study among college students showed that slower growth in forming a coherent set of values and beliefs as well as a healthy sense of identity or self-concept was correlated with lower NFC across 15 months (Njus \& Johnson, 2008); despite that, the direction of effects was not established in that study because it only informed of how 15-month change in NFC was linked to change in mental health-related outcomes during the same period. In another study among university undergraduates that established directionality using ordinary least squares regression, heightened chronic sleep deprivation predicted decrease in NFC and leadership skills over 3 years (Chen \& Chen, 2019). Nonetheless, to the best of our knowledge, whether this pattern of results can be extended to community adults over long durations has not been examined in prior research.

It is also important to consider that the six studies to date that have tested the longitudinal relations between NFC and mental health-relevant constructs (Baer et al., 2013; Chen \& Chen, 2019; Chen \& Zhang, 2020; Gallagher, 2012; Nishiguchi et al., 2016; Njus \& Johnson, 2008) had a major limitation. All of them used ordinary least squares regression or latent growth curve models, which only inform us of between-person, bidirectional relations over time (Grimm, Ram, \& Hamagami, 2011). Also, ordinary least squares regression does not account for clustering of repeated measures within persons across time, which violates the independence or error assumption (Huang, 2018). Of equal or more importance and interest to psychological sciences are the within-person, cross-lagged bidirectional prior level-to-future level relations and change-to-future change associations among NFC and ADS across long durations. This 
endeavor can guide personalized approaches to education, diagnosis, prevention, and intervention (Hayes et al., 2019; Reber, Canning, \& Harackiewicz, 2018; van Os, Delespaul, Wigman, Myin-Germeys, \& Wichers, 2013). Further, testing within-person, cross-lagged, bidirectional, change-to-future-change and level-to-future-level associations between NFC and common ADS is needed in light of increased prevalence of mental health problems across the world in recent years (Kim et al., in press; Nochaiwong et al., 2021). In addition, examining both between-person and within-person NFC-ADS relations is important as their effect sizes could differ in direction and magnitude (Zainal \& Newman, 2021a).

Accordingly, the current study aimed to test the within-person, cross-lagged, bidirectional level-to-future level and change-to-future change relations between NFC and ADS. This study extends previous literature in a number of ways. First, it uses two advanced longitudinal structural equation modeling (SEM) approaches: the random intercept cross-lagged panel model (RI-CLPM; Hamaker, Kuiper, \& Grasman, 2015) and bivariate dual latent change score (BLCS) model (Grimm, Zhang, Hamagami, \& Mazzocco, 2013). These approaches facilitate Granger (or weak) causal inferences by establishing temporal precedence, reducing measurement bias, as well as adjusting for regression to the mean, prior lagged autoregressive effects (i.e., one variable predicting itself at a future time) (Salthouse, 2012; Usami, Hayes, \& McArdle, 2015), and baseline scores. Whereas RI-CLPM informs within-person level-to-future level relations, BLCS relays within-person change-to-future change associations (Usami, Murayama, \& Hamaker, 2019). Thus, based on theory and evidence and using a series of RI-CLPM and BLCS models, we tested the following study hypotheses. First, we predicted that within persons, lower level of NFC at a time-point or greater decrease in NFC at a time-lag would significantly relate to higher level or larger increase in ADS indexed by the Mental Health Inventory-5 (MHI-5; Means- 
Christensen, Arnau, Tonidandel, Bramson, \& Meagher, 2005) at the next time-point or time-lag, and conversely (Hypothesis 1). Our secondary hypothesis would be that between persons, a negative significant cross-sectional association between NFC and ADS would similarly be observed across all time-points (Hypothesis 2).

\section{Method}

\section{Participants}

Participants $(n=6750)$ were community-dwelling adults who were representative of the Dutch general population in the Longitudinal Internet Studies for the Social sciences (LISS) study based at Tilburg University, Netherlands (refer to https://www.lissdata.nl for more details) (Scherpenzeel, Das, Ester, \& Kaczmirek, 2010; van der Velden, Contino, Marchand, Das, \& Schut, 2020). Informed consent was obtained from participants as per institutional review board (IRB) requirements at Tilburg University, Netherlands. Further, since this study used a publicly available dataset, it was exempt from additional IRB approval.

At baseline, the average age was 60.69 years $(S D=8.17$, range $=28-106)$ and $51 \%$ were females. Regarding cultural background, 95.88\% reportedly identified as Dutch, 2.65\% reported being a first- or second-generation foreigner from a Western background, and $1.47 \%$ a first- or second-generation foreigner from a non-Western background. In addition, 13\% of participants reportedly underwent a college education as their highest level of formal schooling, compared to elementary or middle school $(65 \%)$ or high school $(22 \%)$. In addition, baseline mean personal gross monthly income was $€ 4999.84(S D=1773.90$, range $=0-26,000)$.

\section{Procedures}

The current study received ethical approval and all study participants provided voluntary informed consent in adherence to General Data Protection Regulation rules and were reimbursed 
$€ 15$ per hour for their effort (Scherpenzeel \& Das, 2011). Recruitment for the LISS panel study was based on a realistic and stratified probability sampling method of more than 6000 households obtained from official databases (Scherpenzeel et al., 2010). Surveys on sociodemographics, health, cognitive processes, and lifestyle choices, were administered over the Internet. Each survey took about 30-45 minutes to complete and was administered approximately every 1 to 1.5 years from 2008 to 2018 to participating Dutch households (van der Velden, Bosmans, \& Scherpenzeel, 2013). Participants without access to Internet connected devices were offered computer access to finish surveys (Kroesen \& De Vos, 2020).

\section{Measures}

Anxiety and Depression Symptoms. ADS were assessed using the MHI-5 (MeansChristensen et al., 2005) derived from the Short Form Health Survey (Ware \& Sherbourne, 1992). Examples of items include, "I felt very anxious" and "I felt depressed and gloomy." Participants endorsed the frequency they experienced ADS in the past month on a 6-point Likert scale $(1=$ never to $6=$ continuously $)$. The mean score was computed, and greater score indicated more ADS. The MHI-5 has shown excellent internal consistency (Cronbach's $\alpha=.82$ ), construct validity, as well as sensitivity and specificity with numerous clinical interview-based diagnoses (Cuijpers, Smits, Donker, ten Have, \& de Graaf, 2009; Means-Christensen et al., 2005). The internal consistencies herein were good $(\alpha \mathrm{s}=.83-.86)$ across the 10 waves of assessment.

Need for Cognition. The 18-item NFC scale (Cacioppo, Petty, \& Kao, 1984) was used to assess the frequency with which an individual tends to search for, enjoy, and engage in mentally challenging and complex topics, tasks, or problems, continually. Examples of items include, "I would prefer complex to simple problems," and "I really enjoy a task that involves coming up with new solutions to problems." Participants responded on a 7-point Likert scale $(1=$ strongly 
disagree to $7=$ strongly agree). Scores were averaged, and higher score denoted greater traitlevel NFC. The NFC scale has shown high internal consistency $(\alpha=.90-.92)$, strong convergent validity and discriminant validity, as well as 7-week retest reliability $(r=.88)$ (Cacioppo et al., 1984; Olson, Camp, \& Fuller, 1984; Sadowski \& Gulgoz, 1992). In this study, good internal consistency was observed ( $\alpha \mathrm{s}=.87$ to .90$)$ across the 10 time-points.

\section{Data Analyses}

All SEM analyses were conducted using the lavaan package (Rosseel, 2012) in $R$ Version 3.6.3 using the RStudio software. Model fit was evaluated using practical fit indices and rule-ofthumb cut-offs: confirmatory fit indices (CFI; Bentler, 1990; CFI $\geq .95$ ); root mean square error of approximation (RMSEA; Steiger, 1990; RMSEA $\leq .080$ ); square root mean residual (SRMR; Hu \& Bentler, 1999; SRMR $\leq .050$ ). Full information maximum likelihood, the gold standard for data assumed to be missing at random, was used to handle missing data (Graham, 2009). Our study hypotheses were preregistered on Open Science Framework (OSF; https://osf.io/49jt8), and the $R$ Markdown (Allaire et al., 2021; Xie, Allaire, \& Grolemund, 2018; Xie, Dervieux, \& Riederer, 2020) data analytic syntax and output files are available on OSF (https://osf.io/srt3n/). Further, the LISS dataset can be requested under specific conditions following these instructions on their data repository website (https://www.lissdata.nl/access-data). Moreover, the descriptive data (Table S1), correlation matrix (Table S2), and visual plots of variables (Figures S1 to S20), can be obtained in the Online Supplemental Materials (OSM). As reflected in the OSM, all data were normally distributed and no outliers were detected.

First, we conducted a longitudinal measurement invariance (LMI) analysis as an important prerequisite (Widaman, Ferrer, \& Conger, 2010). Longitudinal measurement invariance analyses test the degree to which factor loadings $(\lambda s)$, item intercepts $(\tau s)$, and 
residual variances (Es) of the study measures are equal across the 10 time-points (Millsap \& YunTein, 2004). We evaluated longitudinal measurement invariance following this sequence: (1) Configural (time-invariant one-factor structure of NFC and MHI across time-points); (2) Metric (time-invariant $\lambda s$, but $\tau$ s and $\varepsilon s$ freely varying across time-points); (3) Scalar (time-invariant $\lambda s$ and $\tau \mathrm{s}$, but $\varepsilon s$ freely varying across time-points); (4) Strict (time-invariant $\lambda \mathrm{s}, \tau \mathrm{s}$, and $\varepsilon s$ ). At each level, we tested if there were notable changes in practical fit indices (Meade, Johnson, \& Braddy, 2008). Major changes in practical fit indices when comparing the more (vs. less) constrained models $(\Delta \mathrm{CFI} \leq-.010, \Delta \mathrm{RMSEA} \geq+.015, \Delta \mathrm{SRMR} \geq+.030)$ (Chen, 2007; Zainal, Newman, \& Hong, 2021) indicates that the less constrained model is preferred.

The RI-CLPM was used to accommodate non-independent, repeated-measures observations and to parse variance into trait-level (individual difference) between-person variance and state-level (dynamic) within-person variance (Hamaker et al., 2015). RI-CLPM allowed us to examine these bi-directional within-person cross-lagged relations $(\gamma \mathrm{s})$ over and above between-person variances $(\alpha s)$, within-person autoregressive effects $(\beta s$; level of one construct predicting its future level), and regression to the mean (Falkenström, Finkel, Sandell, Rubel, \& Holmqvist, 2017; Usami, 2020). Our main interest was in the within-person crosslagged relations between level of ADS at one time-point (T-1) and level of NFC at the next successive time-point (T) after a year ( $\gamma \mathrm{s})$ (and vice versa), as denoted in Equations 1 and 2 here.

$$
\begin{aligned}
& \mu(\mathrm{NFC})_{[T]}=\alpha_{\mathrm{Y}} \times(\mathrm{NFC})_{[T-1]}+\beta_{\mathrm{Y}} \times(\mathrm{NFC})_{[T-1]}+\gamma_{\mathrm{X}} \times(\mathrm{ADS})_{[T-1]} \\
& \mu(\mathrm{ADS})_{[T]}=\alpha_{\mathrm{X}} \times(\mathrm{ADS})_{[T-1]}+\beta_{\mathrm{X}} \times(\mathrm{ADS})_{[T-1]}+\gamma_{\mathrm{Y}} \times(\mathrm{NFC})_{[T-1]}
\end{aligned}
$$

Simultaneously, we used BLCS to determine if within-person change in ADS at one time-lag $(\Delta \mathrm{T}-1)$ would be significantly associated with change in NFC at the next adjacent time$\operatorname{lag}(\Delta \mathrm{T})$ (and vice versa). BLCS models are an advanced SEM approach that combines cross- 
lagged panel models and parallel process latent growth models (Ferrer \& McArdle, 2010). It enables the investigation of within-person change-to-future change relations (coupling effects; $\delta s)$ after adjusting for between-person initial status, within-person self-feedback loop (proportional effects; change in a construct predicting future change in itself; $\beta \mathrm{s}$ ), and betweenperson constant change parameters ( $\alpha$ s) (Grimm \& Ram, 2018). BLCS models can be expressed by Equations 3 and 4 below.

$$
\begin{aligned}
& \Delta(\mathrm{NFC})_{[\Delta T]}=\alpha \mathrm{Y} \times(\mathrm{NFC})_{[\Delta T-1]}+\beta_{\mathrm{Y}} \times(\mathrm{NFC})_{[\Delta T-1]}+\delta \mathrm{X} \times(\mathrm{ADS})_{[\Delta T-1]} \\
& \Delta(\mathrm{ADS})_{[\Delta T]}=\alpha \mathrm{X} \times(\mathrm{ADS})_{[\Delta T-1]}+\beta_{\mathrm{X}} \times(\mathrm{ADS})_{[\Delta T-1]}+\delta \mathrm{Y} \times(\mathrm{NFC})_{[\Delta T-1]}
\end{aligned}
$$

Following recommended best practices, the within-person cross-lagged relations $(\gamma \mathrm{s})$ in the RICLPM and within-person coupling effects in the BLCS $(\delta s)$ were fixed to equality across timepoints to minimize standard errors of the parameter estimates (McArdle, 2009; Zainal \& Newman, 2021a). To manage missing data, we used full information maximum likelihood; a gold standard approach in SEM for our dataset that was missing at random (Lee \& Shi, 2021). Additionally, to make the parameter estimates interpretable, Cohen's $d$ effect sizes were calculated using the formula, $d=t \sqrt{ }(2(1-r) / N)$, where $r=\left(t^{2} /\left(t^{2}+d f\right)\right)$ (Dunlap, Cortina, Vaslow, \& Burke, 1996; Dunst, Hamby, \& Trivette, 2004), where $t$ is the unique parameter estimate $t$-statistic, $d f$ is the degrees of freedom of the error term, and $N$ is the sample size. Cohen's $d$ values of $0.2,0.5$, and 0.8 signified small, moderate, and large effects, respectively. Also, based on research, we conducted covariate analyses by adjusting for the following variables: age (Bruine de Bruin, McNair, Taylor, Summers, \& Strough, 2015), extent of formal education (Cacioppo et al., 1996), gender (Double \& Birney, 2016), personal gross monthly income, and cultural background (identification as Dutch or a foreigner) (Padgett et al., 2010).

\section{Power Analysis}


Based on best practice guidelines (Jak, Jorgensen, Verdam, Oort, \& Elffers, 2020), a Monte Carlo power analysis that paralleled the sample size and other conditions of the current study conditions was conducted. The $R$ package, RAMpath (Zhang, 2014; Zhang, Hamagami, Grimm, \& McArdle, 2015), was used to conduct the power analysis. To detect small effect sizes that ranged from $d=0.10-0.20$ for the within-person, cross-lagged, level-to-future level or change-to-future change relations and between-person cross-sectional associations between NFC and SYM, the present study had 100\% power.

\section{Results}

\section{Longitudinal Measurement Invariance}

Tables S3 and S4 present the LMI analyses for the MHI-5 and NFC assessments, respectively. Measurement equivalence was observed for both measures at the Strict level (timeinvariant $\lambda s, \tau s$, and $\varepsilon s)$. Thus, the NFC and ADS constructs were measured along the same scale across the same waves and suitable for longitudinal SEM.

\section{Random-Intercept Cross-Lagged Panel Models}

Table 1 displays the model fit indices and parameter estimates of the RI-CLPM model that investigates if level in ADS was associated with subsequent level in NFC (and vice versa). The RI-CLPM showed excellent model fit $\left(\chi^{2}(d f=197)=773.716, p<.001\right.$, CFI $=.986$, RMSEA $=.016$, SRMR $=.037)$. Within persons, higher prior level of common ADS significantly predicted lower NFC level at the future adjacent time-point $(\gamma=-0.026,95 \%$ CI [$0.041,-0.012], d=-0.498)$. Simultaneously, within persons, lower previous level of NFC significantly forecasted greater ADS at the next successive time-point $(\gamma=-0.058,95 \%$ CI [0.077, -0.039], $d=-0.852$ ). These within-person cross-lagged, level-to-future level effects were observed above and beyond significant positive autoregressive lagged effects of $\mathrm{MHI}(\beta=0.179$, 
$95 \%$ CI $[0.162,0.197], d=2.812)$ and $\operatorname{NFC}(\beta=0.219,95 \%$ CI $[0.189,0.250], d=1.988)$,

baseline scores, between-person effects, and estimated parameters in the RI-CLPM. In addition, supporting Hypothesis 2, between persons, higher random intercept of ADS was significantly related to lower NFC $(\beta=-0.068,95 \%$ CI $[-0.079,-0.057], d=-1.738){ }^{1}$

\section{Bivariate Dual Latent Change Score Models}

Table 2 shows the model fit indices and parameter estimates of the BLCS model that determines if change in ADS was associated with future change in NFC (and vice versa). The BLCS model showed excellent model fit $\left(\chi^{2}(d f=209)=795.684, p<.001, \mathrm{CFI}=.986, \mathrm{RMSEA}\right.$ $=.016, \mathrm{SRMR}=.038)$. Analyses showed that, within persons, 1-year increase in ADS at a prior time-lag was significantly related to future 1-year reduction in NFC at the next successive time$\operatorname{lag}(\delta=-0.509,95 \%$ CI [-0.774, -0.243], $d=-0.519)$. Simultaneously, 1 -year decrease in NFC at a previous time-lag was significantly associated with subsequent 1 -year rise in ADS at the next adjacent time-lag $(\delta=-0.892,95 \%$ CI [-1.275, -0.509], $d=-0.631)$. These notable within-person coupling effects held even after controlling for significant negative within-person autoregressive proportional effects of $\operatorname{ADS}(\beta=-0.095,95 \%$ CI $[-0.145,-0.045], d=-0.514)$ and NFC $(\beta=-$ $0.128,95 \% \mathrm{CI}[-0.192,-0.063], d=-0.533)$, baseline scores, as well as other parameters in the model. Collectively, the results were consistent with Hypotheses 2 and $3 .^{2}$

\footnotetext{
${ }^{1}$ The RI-CLPM that included age, gender, income, education, and cultural background as covariates had good model fit $\left(\chi^{2}(d f=298)=2982.855, p<.001, \mathrm{CFI}=.934, \mathrm{RMSEA}=.025\right.$, $\mathrm{SRMR}=.084)$. Within persons, lower level of ADS significantly predicted higher level of NFC at the next time-point $(\gamma=-0.027,95 \%$ CI $[-0.041,-0.012], d=-0.412)$, and vice versa $(\gamma=-$ $0.059,95 \% \mathrm{CI}[-0.077,-0.040], d=-0.711)$. Also, between persons, greater random intercept NFC was substantially related to lower random intercept ADS ( $\beta=-0.067,95 \%$ CI [-0.078, $0.056], d=-1.413)$.

2 The BLCS model that adjusted for age, gender, education, cultural background, and income displayed acceptable model fit $\left(\chi^{2}(d f=310)=3346.429, p<.001, \mathrm{CFI}=.927\right.$, RMSEA $=.025$, SRMR $=.089)$. Within-person larger 1-year increase in ADS was significantly and
} 


\section{Discussion}

Supporting cognitive processing and scar models, within persons, greater prior decrease in trait NFC was related to higher rise in ADS at the next time-point and time-lag, and conversely. Further, moderate-to-large within-person, level-to-future level and change-to-future change relations between NFC and ADS were consistently observed ( $d=-0.852$ to -0.498$)$. Also, in the RI-CLPM, a large between-person, cross-sectional association between NFC and commonly observed ADS was found at each and every time-point $(d=-1.738)$. Note that these within-person cross-lagged relations emerged even after adjusting for between-person variances, baseline scores, previous lagged effects, and regression to the mean, as well as reducing error due to measurement unreliability. The within-person level-to-future level and change-to-future change relations between NFC and ADS also remained above and beyond age, gender, cultural background, education level, and income as a socio-economic status indicator.

Within persons, reduced level and change in NFC dovetailed with future increased ADS. This result might be explained by theories which propose that, across time, being curious is correlated with higher psychological well-being, adaptive perceptions of the self, future, and world, as well as openness to novel challenges, thinking styles, and experiences (Gallagher \& Lopez, 2007; Kashdan, Rose, \& Fincham, 2004). Further, this finding may be accounted for by the fact that over time, lower NFC tends to coincide with greater adoption of dysfunctional attitudes and cognitive distortions (e.g., overgeneralization, mental filtering, and all-or-none thinking; Berzonsky, 2008; Osberg, Poland, Aguayo, \& MacDougall, 2008). Moreover, decreased NFC likely related to future heightened ADS via corresponding factors, such as lower

\footnotetext{
independently related to future 1-year reduction in NFC at the next time-lag $(\delta=-0.376,95 \%$ CI
} $[-0.617,-0.136], d=-0.354)$, and conversely $(\delta=-0.865,95 \%$ CI $[-1.382,-0.347], d=-0.378)$. 
ambiguity tolerance, poorer problem-solving or resource management skills (Gallagher, 2012;

Rezazadeh \& Zarrinabadi, 2020), and proclivity toward anhedonia, boredom, and mindlessness

(Grass, Strobel, \& Strobel, 2017; Haigh, Moore, Kashdan, \& Fresco, 2010; Watt \& Blanchard, 1994). On that note, compromised NFC probably signals difficulty sustaining attention on tedious tasks that offer short-term low reinforcement but can confer sustained gains in the longterm (Bye \& Pushkar, 2009; Diehl \& Wyrick, 2015). Notably, neuroscientific evidence (Enge, Fleischhauer, Brocke, \& Strobel, 2008; He et al., 2019; Sakaki, Yagi, \& Murayama, 2018) suggest that reduced NFC might predict growth in mental health issues via alterations in attention, cognitive flexibility, and reward-related brain pathways (e.g., dopamine and norepinephrine activity in the substantia nigra, striatum, etc.). Future prospective panel and ecological momentary assessment studies can examine the validity of these propositions.

Simultaneously, why did prior heightened level and change of ADS coincide with future reduction in trait NFC within persons? One possible account is that increased ADS negatively impacts willingness to invest in mental effort across long durations by dampening enthusiasm and decreasing frequency of engagement with intellectually stimulating and lifestyle-enhancing activities (Hess, Emery, \& Neupert, 2012). It is also plausible that the within-person, negative, level-to-future level and change-to-future change relations between ADS and NFC can be explained by greater avoidance and lack of optimal approach behaviors (Denneson, Smolenski, Bush, \& Dobscha, 2017). Taken together, these findings aligned with the scar model (Zainal \& Newman, 2021c; Zainal \& Newman, 2021a) which argues that repeated or prolonged experiences of heightened ADS can adversely alter personality, trait motivation, cognitive styles, and related risk factors. 
Salient between-person, cross-sectional findings also emerged, such that lower NFC was correlated with elevated ADS across each and every time-point, even after controlling for withinperson and other effects in the RI-CLPM. This finding can be explained by the fact that, akin to dispositional curiosity, lower NFC tended to be associated with greater intolerance and suboptimal ways of coping with uncertainty, ambiguity, and novelty across diverse challenging yet possibly gratifying and enriching situations (Kashdan et al., 2009; Koerner, Mejia, \& Kusec, 2017). It is also consistent with data that stronger dispositional curiosity dovetailed with various indices of psychological well-being, such as sense of purpose and meaning, life satisfaction, and growth-facilitating actions (Kashdan \& Steger, 2007).

The current study has some limitations. First, self-report measures were used to assess NFC and common ADS. Future studies could test if the pattern of results extend to various clinician-rated psychiatric diagnoses to determine the transdiagnostic nature of low NFC (cf. deficits in the cognitive control and positive valence systems in the Research Domain Criteria (RDoC); Mitchell \& Sevigny-Resetco, 2020; Santens, Claes, Dierckx, \& Dom, 2020). Additionally, data on ethnic identification was not collected in this study. Future studies could test the current study hypotheses in a more culturally diverse sample. Also, unmeasured variables (e.g., level of dysfunctional attitude) (Petty et al., 2009) may moderate within-person crosslagged relations between NFC and ADS; an area worthy of further investigation for the clinical and personality sciences. Limitations notwithstanding, study strengths include the large sample size, long duration with 10 waves of assessment, and advanced statistical approach. By enhancing our understanding on the level-to-future level and change-to-future change relations between NFC and common ADS, our use of longitudinal SEM addresses a key knowledge gap on psychopathology-personality trait associations (Durbin \& Hicks, 2014). 
If findings are replicated, some implications for the psychological sciences in many applied contexts merit attention. Based on existing evidence (De Fruyt, Van Leeuwen, Bagby, Rolland, \& Rouillon, 2006; Tang et al., 2009), clinical science might profit from examining how psychotherapy could over time alter trait NFC. Theory and data (Farrell, Deacon, Dixon, \& Lickel, 2013; Maldonato et al., 2017; Oh \& Kang, 2019; Ruiter, Verplanken, De Cremer, \& Kok, 2004) imply that this could be achieved by strengthening cognitive behavioral therapy (CBT) strategies. CBT techniques (e.g., cognitive reframing, exposure) can be augmented to enhance NFC by helping patients to be in the moment and discover joy in the process as opposed to being totally outcome focused. This could include simultaneously engaging them in intellectual and thought-provoking activities and topics that require heavy investment in mental effort but engaging in self talk to appraise those efforts as enjoyable or to actively try to discover the joy in those activities and trying to feel a sense of accomplishment in those efforts. Furthermore, clients could be guided to make conscious efforts to rediscover their childlike curiosity toward learning about the world and discovery. Patients could regularly be guided to work on solving puzzles and learning about complex current affairs while engaging in self-talk in positive mood-inducing ways. It could also involve helping clients rediscover joy in learning that they may have had at one time, but lost as external pressures became their focus. It may also be effective to augment traditional CBT approaches by assisting patients with low NFC to engage in self-talk in curious ways as well as to connect them with work, hobbies, and activities that instill joy and excitement. During such therapeutic conversations, emphasis could be placed on the process rather than the outcome of their goal-directed endeavors to eliminate worries and pessimism. Also, it is possible that a therapist could appeal to somebody low in NFC using some sort of motivational interviewing strategy (Csillik, 2014). In line with recent treatments that focus on increasing 
positive emotion (Geschwind, Peeters, Drukker, van Os, \& Wichers, 2011; Kim \& Franklin, 2015), a lack of interest in learning and general curiosity about the world likely is contributing to a lack of joy in the person's life. It may be that the first step in changing somebody's NFC is motivating them to make the effort to make changes. Thus, motivational interviewing could be used to help clients realize that NFC could help them enjoy their lives more.

In addition, our findings might translate to NFC serving as either a moderator or predictor of psychotherapy outcomes. These ideas are consistent with initial evidence for face-to-face (Cramer, Bryson, Gardner, \& Webber, 2016; Kelders, Bohlmeijer, \& Van Gemert-Pijnen, 2013) and digital health therapies (Nikoloudakis et al., 2018) that try to tailor ways to raise the odds of patients with increased ADS to buy into the treatment rationale based on their trait NFC level. For example, it may be particularly useful to aid patients low in NFC to become more selfreinforcing by labelling problems as opportunities for growth as opposed to events beyond their coping resources. Given its nascency, the idea of NFC as a treatment moderator awaits more empirical testing. Also, accruing data from the education realm (Giles et al., 2010; Gray, Chang, \& Anderman, 2015; Karagiannopoulou, Milienos, \& Rentzios, 2020) suggest that targeting NFC by teaching critical and deep thinking skills, encouraging creativity, and raising self-efficacy, can lower the chances for elevated ADS. 


\section{References}

Allaire, J., Xie, Y., McPherson, J., Luraschi, J., Ushey, K., Atkins, A., . . Iannone, R. (2021). rmarkdown: Dynamic documents for R. R package version 2.9. URL https://rmarkdown.rstudio.com.

Allemand, M., Grünenfelder-Steiger, A. E., \& Flückiger, C. (2018). Scar model. In V. ZeiglerHill \& T. K. Shackelford (Eds.), Encyclopedia of Personality and Individual Differences (pp. 1-4). Cham: Springer International Publishing. doi:10.1007/978-3-319-28099-8_8551

Baer, L. H., Tabri, N., Blair, M., Bye, D., Li, K. Z., \& Pushkar, D. (2013). Longitudinal associations of need for cognition, cognitive activity, and depressive symptomatology with cognitive function in recent retirees. The Journals of Gerontology, Series B: Psychological Sciences and Social Sciences, 68, 655-664. doi:10.1093/geronb/gbs1 12

Barron, D., Furnham, A., Weis, L., Morgan, K. D., Towell, T., \& Swami, V. (2018). The relationship between schizotypal facets and conspiracist beliefs via cognitive processes. Psychiatry Research, 259, 15-20. doi:10.1016/j.psychres.2017.10.001

Bentler, P. M. (1990). Comparative fit indexes in structural models. Psychological Bulletin, 107, 238-246. doi:10.1037/0033-2909.107.2.238

Bertha, E. A., \& Balázs, J. (2013). Subthreshold depression in adolescence: A systematic review. European Child \& Adolescent Psychiatry, 22, 589-603. doi:10.1007/s00787-013-0411-0

Berzonsky, M. D. (2008). Identity formation: The role of identity processing style and cognitive processes. Personality and Individual Differences, 44, 645-655. doi:10.1016/j.paid.2007.09.024 
Blackwell, M., \& Glynn, A. N. (2018). How to make causal inferences with time-series crosssectional data under selection on observables. American Political Science Review, 112, 1067-1082. doi:10.1017/S0003055418000357

Bruine de Bruin, W., McNair, S. J., Taylor, A. L., Summers, B., \& Strough, J. (2015). "Thinking about numbers is not my idea of fun": Need for cognition mediates age differences in numeracy performance. Medical Decision Making, 35, 22-26.

doi:10.1177/0272989X14542485

Bye, D., \& Pushkar, D. (2009). How need for cognition and perceived control are differentially linked to emotional outcomes in the transition to retirement. Motivation and Emotion, 33, 320-332. doi:10.1007/s11031-009-9135-3

Cacioppo, J. T., \& Petty, R. E. (1982). The need for cognition. Journal of Personality and Social Psychology, 42, 116-131. doi:10.1037/0022-3514.42.1.116

Cacioppo, J. T., Petty, R. E., \& Kao, C. F. (1984). The efficient assessment of need for cognition. Journal of Personality Assessment, 48, 306-307. doi:10.1207/s15327752jpa4803_13

Cacioppo, J. T., Petty, R. E., Feinstein, J. A., \& Jarvis, W. B. G. (1996). Dispositional differences in cognitive motivation: The life and times of individuals varying in need for cognition. Psychological Bulletin, 119, 197-253. doi:10.1037/0033-2909.119.2.197

Cacioppo, J. T., Petty, R. E., Kao, C. F., \& Rodriguez, R. (1986). Central and peripheral routes to persuasion: An individual difference perspective. Journal of Personality and Social Psychology, 51, 1032-1043. doi:10.1037/0022-3514.51.5.1032

Chen, F. F. (2007). Sensitivity of goodness of fit indexes to lack of measurement invariance. Structural Equation Modeling, 14, 464-504. doi:10.1080/10705510701301834 
Chen, P., \& Zhang, J. (2020). Development of Chinese junior high school students' creative potential: Within-person and between-person effects of student-student support and need for cognition. Frontiers in Psychology, 11, 552831. doi:10.3389/fpsyg.2020.552831

Chen, W.-L., \& Chen, J.-H. (2019). Sleep deprivation and the development of leadership and need for cognition during the college years. Journal of Adolescence, 73, 95-99. doi:10.1016/j.adolescence.2019.04.003

Cohen, A. R., Stotland, E., \& Wolfe, D. M. (1955). An experimental investigation of need for cognition. The Journal of Abnormal and Social Psychology, 51, 291-294. doi:10.1037/h0042761

Cramer, R. J., Bryson, C. N., Gardner, B. O., \& Webber, W. B. (2016). Can preferences in information processing aid in understanding suicide risk among emerging adults? Death Studies, 40, 383-391. doi:10.1080/07481187.2016.1166161

Csillik, A. (2014). Positive motivational interviewing: Activating clients's strengths and intrinsic motivation to change. Journal of Contemporary Psychotherapy, 45, 119-128. doi:10.1007/s10879-014-9288-6

Cuijpers, P., Smits, N., Donker, T., ten Have, M., \& de Graaf, R. (2009). Screening for mood and anxiety disorders with the five-item, the three-item, and the two-item Mental Health Inventory. Psychiatry Research, 168, 250-255. doi:10.1016/j.psychres.2008.05.012

Culbreth, A., Westbrook, A., \& Barch, D. (2016). Negative symptoms are associated with an increased subjective cost of cognitive effort. Journal of Abnormal Psychology, 125, 528536. doi:10.1037/abn0000153 
Curran, E., Rosato, M., Ferry, F., \& Leavey, G. (2020). Prevalence and factors associated with anxiety and depression in older adults: Gender differences in psychosocial indicators. Journal of Affective Disorders, 267, 114-122. doi:10.1016/j.jad.2020.02.018

Dalgleish, T., \& Werner-Seidler, A. (2014). Disruptions in autobiographical memory processing in depression and the emergence of memory therapeutics. Trends in Cognitive Sciences, 18, 596-604. doi:10.1016/j.tics.2014.06.010

De Fruyt, F., Van Leeuwen, K., Bagby, R. M., Rolland, J.-P., \& Rouillon, F. (2006). Assessing and interpreting personality change and continuity in patients treated for major depression. Psychological Assessment, 18, 71-80. doi:10.1037/1040-3590.18.1.71

Denneson, L. M., Smolenski, D. J., Bush, N. E., \& Dobscha, S. K. (2017). Curiosity improves coping efficacy and reduces suicidal ideation severity among military veterans at risk for suicide. Psychiatry Research, 249, 125-131. doi:10.1016/j.psychres.2017.01.018

Deschênes, S. S., Burns, R. J., \& Schmitz, N. (2018). Trajectories of anxiety symptoms and associations with incident cardiovascular disease in adults with type 2 diabetes. Journal of Psychosomatic Research, 104, 95-100. doi:10.1016/j.jpsychores.2017.11.015

Diehl, V. A., \& Wyrick, M. (2015). The relationships between need for cognition, boredom proneness, task engagement, and test performance. SAGE Open, 5, 2158244015585606. doi: $10.1177 / 2158244015585606$

Double, K. S., \& Birney, D. P. (2016). The effects of personality and metacognitive beliefs on cognitive training adherence and performance. Personality and Individual Differences, 102, 7-12. doi:10.1016/j.paid.2016.04.101 
Dunlap, W. P., Cortina, J. M., Vaslow, J. B., \& Burke, M. J. (1996). Meta-analysis of experiments with matched groups or repeated measures designs. Psychological Methods, 1, 170-177. doi:10.1037/1082-989x.1.2.170

Dunst, C. J., Hamby, D. W., \& Trivette, C. M. (2004). Guidelines for calculating effect sizes for practice-based research syntheses. Centerscope, 3, 1-10.

Durbin, C. E., \& Hicks, B. M. (2014). Personality and psychopathology: A stagnant field in need of development. European Journal of Personality, 28, 362-386. doi:10.1002/per.1962

Enge, S., Fleischhauer, M., Brocke, B., \& Strobel, A. (2008). Neurophysiological measures of involuntary and voluntary attention allocation and dispositional differences in need for cognition. Personality and Social Psychology Bulletin, 34, 862-874. doi:10.1177/0146167208315556

Falkenström, F., Finkel, S., Sandell, R., Rubel, J. A., \& Holmqvist, R. (2017). Dynamic models of individual change in psychotherapy process research. Journal of Consulting and Clinical Psychology, 85, 537-549. doi:10.1037/ccp0000203

Farrell, N. R., Deacon, B. J., Dixon, L. J., \& Lickel, J. J. (2013). Theory-based training strategies for modifying practitioner concerns about exposure therapy. Journal of Anxiety Disorders, 27, 781-787. doi:10.1016/j.janxdis.2013.09.003

Feist, G. J. (2012). Predicting interest in and attitudes toward science from personality and need for cognition. Personality and Individual Differences, 52, 771-775. doi:10.1016/j.paid.2012.01.005

Ferrer, E., \& McArdle, J. J. (2010). Longitudinal modeling of developmental changes in psychological research. Current Directions in Psychological Science, 19, 149-154. doi:10.1177/0963721410370300 
Fleischhauer, M., Enge, S., Brocke, B., Ullrich, J., Strobel, A., \& Strobel, A. (2010). Same or different? Clarifying the relationship of need for cognition to personality and intelligence. Personality and Social Psychology Bulletin, 36, 82-96. doi:10.1177/0146167209351886

Gallagher, M. W., \& Lopez, S. J. (2007). Curiosity and well-being. The Journal of Positive Psychology, 2, 236-248. doi:10.1080/17439760701552345

Gallagher, V. C. (2012). Managing resources and need for cognition: Impact on depressed mood at work. Personality and Individual Differences, 53, 534-537. doi:10.1016/j.paid.2012.04.025

Gartner, A., Grass, J., Wolff, M., Goschke, T., Strobel, A., \& Strobel, A. (2021). No relation of need for cognition to basic executive functions. Journal of Personality. doi:10.1111/jopy.12639

Gauthier, K. J., Christopher, A. N., Walter, M. I., Mourad, R., \& Marek, P. (2006). Religiosity, religious doubt, and the need for cognition: Their interactive relationship with life satisfaction. Journal of Happiness Studies, 7, 139-154. doi:10.1007/s10902-005-1916-0

Geschwind, N., Peeters, F., Drukker, M., van Os, J., \& Wichers, M. (2011). Mindfulness training increases momentary positive emotions and reward experience in adults vulnerable to depression: a randomized controlled trial. Journal of Consulting and Clinical Psychology, 79, 618-628. doi:10.1037/a0024595

Giles, S. M., Pankratz, M. M., Ringwalt, C., Hansen, W. B., Dusenbury, L., \& Jackson-Newsom, J. (2010). Teachers' delivery skills and substance use prevention program outcomes: The moderating role of students' need for cognition and impulse decision making. Journal of Drug Education, 40, 395-410. doi:10.2190/DE.40.4.e 
Graham, J. W. (2009). Missing data analysis: Making it work in the real world. Annual Review of Psychology, 60, 549-576. doi:10.1146/annurev.psych.58.110405.085530

Granger, C. W. J. (1969). Investigating causal relations by econometric models and crossspectral methods. Econometrica, 37, 424-438. doi:10.2307/1912791

Grass, J., Strobel, A., \& Strobel, A. (2017). Cognitive investments in academic success: The role of need for cognition at university. Frontiers in Psychology, 8, 790. doi:10.3389/fpsyg.2017.00790

Gray, D. L., Chang, Y., \& Anderman, E. M. (2015). Conditional effects of mastery goal structure on changes in students' motivational beliefs: Need for cognition matters. Learning and Individual Differences, 40, 9-21. doi:10.1016/j.lindif.2015.03.025

Grimm, K., Zhang, Z., Hamagami, F., \& Mazzocco, M. (2013). Modeling nonlinear change via latent change and latent acceleration frameworks: Examining velocity and acceleration of growth trajectories. Multivariate Behavioral Research, 48, 117-143. doi:10.1080/00273171.2012.755111

Grimm, K. J., \& Ram, N. (2018). Latent growth and dynamic structural equation models. Annual Review of Clinical Psychology, 14, 55-89. doi:10.1146/annurev-clinpsy-050817-084840

Grimm, K. J., Ram, N., \& Hamagami, F. (2011). Nonlinear growth curves in developmental research. Child Development, 82, 1357-1371. doi:10.1111/j.1467-8624.2011.01630.x

Haigh, E. A. P., Moore, M. T., Kashdan, T. B., \& Fresco, D. M. (2010). Examination of the factor structure and concurrent validity of the Langer mindfulness/mindlessness scale. Assessment, 18, 11-26. doi:10.1177/1073191110386342 
Haller, H., Cramer, H., Lauche, R., Gass, F., \& Dobos, G. J. (2014). The prevalence and burden of subthreshold generalized anxiety disorder: A systematic review. BMC Psychiatry, 14, 128. doi:10.1186/1471-244X-14-128

Hamaker, E. L., Kuiper, R. M., \& Grasman, R. P. P. P. (2015). A critique of the cross-lagged panel model. Psychological Methods, 20, 102-116. doi:10.1037/a0038889

Hayes, S. C., Hofmann, S. G., Stanton, C. E., Carpenter, J. K., Sanford, B. T., Curtiss, J. E., \& Ciarrochi, J. (2019). The role of the individual in the coming era of process-based therapy. Behaviour Research and Therapy, 117, 40-53. doi:10.1016/j.brat.2018.10.005

He, L., Zhuang, K., Li, Y., Sun, J., Meng, J., Zhu, W., . . Qiu, J. (2019). Brain flexibility associated with need for cognition contributes to creative achievement. Psychophysiology, 56, e13464. doi:10.1111/psyp.13464

Hess, T. M., Emery, L., \& Neupert, S. D. (2012). Longitudinal relationships between resources, motivation, and functioning. Journals of Gerontology Series B: Psychological Sciences and Social Sciences, 67, 299-308. doi:10.1093/geronb/gbr100

Hill, B. D., \& Aita, S. L. (2018). The positive side of effort: A review of the impact of motivation and engagement on neuropsychological performance. Applied Neuropsychology: Adult, 25, 312-317. doi:10.1080/23279095.2018.1458502

Hill, B. D., Foster, J. D., Sofko, C., Elliott, E. M., \& Shelton, J. T. (2016). The interaction of ability and motivation: Average working memory is required for Need for Cognition to positively benefit intelligence and the effect increases with ability. Personality and Individual Differences, 98, 225-228. doi:10.1016/j.paid.2016.04.043

Hill, B. D., Foster, J. D., Elliott, E. M., Shelton, J. T., McCain, J., \& Gouvier, W. D. (2013). Need for cognition is related to higher general intelligence, fluid intelligence, and 
crystallized intelligence, but not working memory. Journal of Research in Personality, 47, 22-25. doi:10.1016/j.jrp.2012.11.001

Hu, L., \& Bentler, P. M. (1999). Cutoff criteria for fit indexes in covariance structure analysis: Conventional criteria versus new alternatives. Structural Equation Modeling, 6, 1-55. doi:10.1080/10705519909540118

Huang, F. L. (2018). Multilevel modeling and ordinary least squares regression: How comparable are they? Journal of Experimental Education, 86, 265-281. doi:10.1080/00220973.2016.1277339

Iannello, P., Mottini, A., Tirelli, S., Riva, S., \& Antonietti, A. (2017). Ambiguity and uncertainty tolerance, need for cognition, and their association with stress. A study among Italian practicing physicians. Medical Education Online, 22, 1270009.

doi:10.1080/10872981.2016.1270009

Jak, S., Jorgensen, T. D., Verdam, M. G. E., Oort, F. J., \& Elffers, L. (2020). Analytical power calculations for structural equation modeling: A tutorial and Shiny app. Behavior Research Methods. doi:10.3758/s13428-020-01479-0

Karagiannopoulou, E., Milienos, F. S., \& Rentzios, C. (2020). Grouping learning approaches and emotional factors to predict students' academic progress. International Journal of School \& Educational Psychology, 1-18. doi:10.1080/21683603.2020.1832941

Kashdan, T. B., \& Steger, M. F. (2007). Curiosity and pathways to well-being and meaning in life: Traits, states, and everyday behaviors. Motivation and Emotion, 31, 159-173. doi:10.1007/s11031-007-9068-7 
Kashdan, T. B., Rose, P., \& Fincham, F. D. (2004). Curiosity and exploration: Facilitating positive subjective experiences and personal growth opportunities. Journal of Personality Assessment, 82, 291-305. doi:10.1207/s15327752jpa8203_05

Kashdan, T. B., Gallagher, M. W., Silvia, P. J., Winterstein, B. P., Breen, W. E., Terhar, D., \& Steger, M. F. (2009). The curiosity and exploration inventory-II: Development, factor structure, and psychometrics. Journal of Research in Personality, 43, 987-998. doi:10.1016/j.jrp.2009.04.011

Kelders, S. M., Bohlmeijer, E. T., \& Van Gemert-Pijnen, J. E. W. C. (2013). Participants, usage, and use patterns of a web-based intervention for the prevention of depression within a randomized controlled trial. Journal of Medical Internet Research, 15, e172. doi:10.2196/jmir.2258

Kim, H., Rackoff, G. N., Fitzimmons-Craft, E., Shin, K. E., Zainal, N. H., Schwob, J. T., .. . Newman, M. G. ( in press). College mental health before and during COVID-19: Results from a nationwide survey. Cognitive Therapy and Research, 1-10. doi:10.1007/s10608$021-10241-5$

Kim, J. S., \& Franklin, C. (2015). Understanding emotional change in solution-focused brief therapy: Facilitating positive emotions. Best Practices in Mental Health: An International Journal, 11, 25-41.

Koerner, N., Mejia, T., \& Kusec, A. (2017). What's in a name? Intolerance of uncertainty, other uncertainty-relevant constructs, and their differential relations to worry and generalized anxiety disorder. Cognitive Behaviour Therapy, 46, 141-161. doi:10.1080/16506073.2016.1211172 
Kroesen, M., \& De Vos, J. (2020). Does active travel make people healthier, or are healthy people more inclined to travel actively? Journal of Transport \& Health, 16. doi:10.1016/j.jth.2020.100844

Lachlan, K. A., Hutter, E., Gilbert, C., \& Spence, P. R. (2021). Need for cognition and rumination: Alternate explanations for sex differences in disaster information seeking. Progress in Disaster Science, 11. doi:10.1016/j.pdisas.2021.100180

Lee, T., \& Shi, D. (2021). A comparison of full information maximum likelihood and multiple imputation in structural equation modeling with missing data. Psychological Methods. doi: $10.1037 /$ met0000381

Luong, C., Strobel, A., Wollschläger, R., Greiff, S., Vainikainen, M.-P., \& Preckel, F. (2017). Need for cognition in children and adolescents: Behavioral correlates and relations to academic achievement and potential. Learning and Individual Differences, 53, 103-113. doi:10.1016/j.lindif.2016.10.019

Maldonato, N., Sperandeo, R., Costa, V. n., Cioffi, V., Cozzolino, P., Santo, R. D., . . Scognamiglio, C. (2017). Does brain sweat pay off? The association between the need for cognition and cognitive function among the American elderly. Journal of Psychology \& Psychotherapy, 7, 1-6. doi:10.4172/2161-0487.1000326

Maloney, E. A., \& Retanal, F. (2020). Higher math anxious people have a lower need for cognition and are less reflective in their thinking. Acta Psychologica, 202, 102939. doi:10.1016/j.actpsy.2019.102939

McArdle, J. J. (2009). Latent variable modeling of differences and changes with longitudinal data. Annual Review of Psychology, 60, 577-605. doi:10.1146/annurev.psych.60.110707.163612 
Meade, A. W., Johnson, E. C., \& Braddy, P. W. (2008). Power and sensitivity of alternative fit indices in tests of measurement invariance. Journal of Applied Psychology, 93, 568-592. doi:10.1037/0021-9010.93.3.568

Means-Christensen, A. J., Arnau, R. C., Tonidandel, A. M., Bramson, R., \& Meagher, M. W. (2005). An efficient method of identifying major depression and panic disorder in primary care. Journal of Behavioral Medicine, 28, 565-572. doi:10.1007/s10865-0059023-6

Meier, E., Vogl, K., \& Preckel, F. (2014). Motivational characteristics of students in gifted classes: The pivotal role of need for cognition. Learning and Individual Differences, 33, 39-46. doi:10.1016/j.lindif.2014.04.006

Millsap, R. E., \& Yun-Tein, J. (2004). Assessing factorial invariance in ordered-categorical measures. Multivariate Behavioral Research, 39, 479-515. doi:10.1207/S15327906MBR3903_4

Mitchell, S. H., \& Sevigny-Resetco, D. (2020). Effort-related decision-making in ADHD. Journal of Psychiatry and Brain Science, 5. doi:10.20900/jpbs.20200027

Nikoloudakis, I. A., Crutzen, R., Rebar, A. L., Vandelanotte, C., Quester, P., Dry, M., ... Short, C. E. (2018). Can you elaborate on that? Addressing participants' need for cognition in computer-tailored health behavior interventions. Health Psychology Review, 12, 437-452. doi: $10.1080 / 17437199.2018 .1525571$

Nishiguchi, Y., Takano, K., \& Tanno, Y. (2016). The need for cognition mediates and moderates the association between depressive symptoms and impaired effortful control. Psychiatry Research, 241, 8-13. doi:10.1016/j.psychres.2016.04.092 
Njus, D., \& Johnson, D. R. (2008). Need for cognition as a predictor of psychosocial identity development. The Journal of Psychology, 142, 645-655. doi:10.3200/jrlp.142.6.645-655

Nochaiwong, S., Ruengorn, C., Thavorn, K., Hutton, B., Awiphan, R., Phosuya, C., .. . Wongpakaran, T. (2021). Global prevalence of mental health issues among the general population during the coronavirus disease-2019 pandemic: a systematic review and metaanalysis. Scientific Reports, 11, 10173. doi:10.1038/s41598-021-89700-8

Oh, J., \& Kang, J.-h. (2019). Converting a digital minority into a digital beneficiary: Digital skills to improve the need for cognition among Korean older adults. Information Development, 37, 21-31. doi:10.1177/0266666919888570

Olson, K., Camp, C., \& Fuller, D. (1984). Curiosity and need for cognition. Psychological Reports, 54, 71-74. doi:10.2466/pr0.1984.54.1.71

Osberg, T. M., Poland, D., Aguayo, G., \& MacDougall, S. (2008). The Irrational Food Beliefs Scale: Development and validation. Eating Behaviors, 9, 25-40. doi:10.1016/j.eatbeh.2007.02.001

Padgett, R. D., Goodman, K. M., Johnson, M. P., Saichaie, K., Umbach, P. D., \& Pascarella, E. T. (2010). The impact of college student socialization, social class, and race on need for cognition. New Directions for Institutional Research, 2010, 99-111. doi:10.1002/ir.324

Patel, D. (2017). Indira Gandhi: The power to question is the basis of all human progress.

Patzelt, E. H., Kool, W., Millner, A. J., \& Gershman, S. J. (2019). The transdiagnostic structure of mental effort avoidance. Scientific Reports, 9, 1689. doi:10.1038/s41598-018-37802-1

Pearl, J. (2009). Causality and structural models in social science and economics Causality: Models, reasoning and inference (pp. 133-172). doi:10.1017/cbo9780511803161.007 
Petty, R. E., Brinol, P., Loersch, C., \& McCaslin, M. J. (2009). The need for cognition. In M. R. Leary \& R. H. Hoyle (Eds.), Handbook of individual differences in social behavior (pp. 318-329). New York, NY: Guilford Press.

Reber, R., Canning, E. A., \& Harackiewicz, J. M. (2018). Personalized education to increase interest. Current Directions in Psychological Science, 27, 449-454.

doi:10.1177/0963721418793140

Reeves, A. L., Watson, P. J., Ramsey, A., \& Morris, R. J. (1995). Private self-consciousness factors, need for cognition, and depression. Journal of Social Behavior \& Personality, 10, 431-443.

Rezazadeh, M., \& Zarrinabadi, N. (2020). Examining need for closure and need for cognition as predictors of foreign language anxiety and enjoyment. Journal of Multilingual and Multicultural Development, 1-13. doi:10.1080/01434632.2020.1798972

Rodríguez, M. R., Nuevo, R., Chatterji, S., \& Ayuso-Mateos, J. L. (2012). Definitions and factors associated with subthreshold depressive conditions: a systematic review. $B M C$ Psychiatry, 12, 181. doi:10.1186/1471-244X-12-181

Rosseel, Y. (2012). Lavaan: An R package for structural equation modeling. Journal of Statistical Software, 48, 1-36. doi:10.18637/jss.v048.i02

Ruiter, R. A. C., Verplanken, B., De Cremer, D., \& Kok, G. (2004). Danger and fear control in response to fear appeals: The role of need for cognition. Basic and Applied Social Psychology, 26, 13-24. doi:10.1207/s15324834basp2601_2

Rzewuska, M., Mallen, C. D., Strauss, V. Y., Belcher, J., \& Peat, G. (2015). One-year trajectories of depression and anxiety symptoms in older patients presenting in general 
practice with musculoskeletal pain: A latent class growth analysis. Journal of Psychosomatic Research, 79, 195-201. doi:10.1016/j.jpsychores.2015.05.016

Sadowski, C. J., \& Gulgoz, S. (1992). Internal consistency and test-retest reliability of the need for cognition scale. Perceptual and Motor Skills, 74, 610-610. doi:10.2466/pms.1992.74.2.610

Sakaki, M., Yagi, A., \& Murayama, K. (2018). Curiosity in old age: A possible key to achieving adaptive aging. Neuroscience \& Biobehavioral Reviews, 88, 106-116. doi:10.1016/j.neubiorev.2018.03.007

Salthouse, T. A. (2012). Does the direction and magnitude of cognitive change depend on initial level of ability? Intelligence, 40, 352-361. doi:10.1016/j.intell.2012.02.006

Sandra, D. A., \& Otto, A. R. (2018). Cognitive capacity limitations and Need for Cognition differentially predict reward-induced cognitive effort expenditure. Cognition, 172, 101106. doi:10.1016/j.cognition.2017.12.004

Santens, E., Claes, L., Dierckx, E., \& Dom, G. (2020). Effortful control - A transdiagnostic dimension underlying internalizing and externalizing psychopathology. Neuropsychobiology, 79, 255-269. doi:10.1159/000506134

Scherpenzeel, A., \& Das, M. (2011). True longitudinal and probability-based internet panels: Evidence from the Netherlands. In M. Das, P. Ester \& L. Kaczmirek (Eds.), Social and behavioral research and the internet: Advances in applied methods and research strategies (pp. 77-104). New York: Taylor \& Francis. doi:10.4324/9780203844922

Scherpenzeel, A., Das, J. W. M., Ester, P., \& Kaczmirek, L. (2010). 'True' longitudinal and probability-based internet panels: Evidence from the Netherlands. In J. W. M. Das, P. 
Ester \& L. Kaczmirek (Eds.), Social and behavioral research and the internet (pp. 77103). London, UK: Taylor \& Francis.

Schmidt, N. B., Lerew, D. R., \& Joiner, T. E. (2000). Prospective evaluation of the etiology of anxiety sensitivity: Test of a scar model. Behaviour Research and Therapy, 38, 10831095. doi:10.1016/S0005-7967(99)00138-2

Schofield, D. J., Shrestha, R. N., Percival, R., Passey, M. E., Callander, E. J., \& Kelly, S. J. (2011). The personal and national costs of mental health conditions: Impacts on income, taxes, government support payments due to lost labour force participation. BMC Psychiatry, 11, 72. doi:10.1186/1471-244X-11-72

Shi, J., Chen, Z., \& Tian, M. (2010). Internet self-efficacy, the need for cognition, and sensation seeking as predictors of problematic use of the Internet. Cyberpsychology, Behavior, and Social Networking, 14, 231-234. doi:10.1089/cyber.2009.0462

Skagen, K., \& Collins, A. M. (2016). The consequences of sickness presenteeism on health and wellbeing over time: A systematic review. Social Science \& Medicine, 161, 169-177. doi:10.1016/j.socscimed.2016.06.005

Steiger, J. H. (1990). Structural model evaluation and modification: An interval estimation approach. Multivariate Behavioral Research, 25, 173-180. doi:10.1207/s15327906mbr2502_4

Tang, T. Z., DeRubeis, R. J., Hollon, S. D., Amsterdam, J., Shelton, R., \& Schalet, B. (2009). Personality change during depression treatment: A placebo-controlled trial. Archives of General Psychiatry, 66, 1322-1330. doi:10.1001/archgenpsychiatry.2009.166

Thompson, E. P., Chaiken, S., \& Hazlewood, J. D. (1993). Need for cognition and desire for control as moderators of extrinsic reward effects: A person $\times$ situation approach to the 
study of intrinsic motivation. Journal of Personality and Social Psychology, 64, 987-999. doi:10.1037/0022-3514.64.6.987

Tomljenovic, H., \& Bubic, A. (2019). Cognitive and emotional factors in health behaviour: Dual-process reasoning, cognitive styles and optimism as predictors of healthy lifestyle, healthy behaviours and medical adherence. Current Psychology, 40, 3256-3264. doi:10.1007/s12144-019-00268-z

Usami, S. (2020). On the differences between general cross-lagged panel model and randomintercept cross-lagged panel model: Interpretation of cross-lagged parameters and model choice. Structural Equation Modeling, 1-14. doi:10.1080/10705511.2020.1821690

Usami, S., Hayes, T., \& McArdle, J. J. (2015). On the mathematical relationship between latent change score and autoregressive cross-lagged factor approaches: Cautions for inferring causal relationship between variables. Multivariate Behavioral Research, 50, 676-687. doi:10.1080/00273171.2015.1079696

Usami, S., Murayama, K., \& Hamaker, E. L. (2019). A unified framework of longitudinal models to examine reciprocal relations. Psychological Methods, 24, 637-657. doi:10.1037/met0000210

van der Velden, P. G., Bosmans, M. W., \& Scherpenzeel, A. C. (2013). The burden of research on trauma for respondents: a prospective and comparative study on respondents evaluations and predictors. PLoS ONE, 8, e 77266. doi:10.1371/journal.pone.0077266 van der Velden, P. G., Contino, C., Marchand, M., Das, M., \& Schut, H. (2020). Does pre-event lack of emotional support increase the risk of post-event PTSD, anxiety, depression symptoms and lack of support? A comparative population-based study among victims of 
threat and violence. Journal of Anxiety Disorders, 75, 102269.

doi:10.1016/j.janxdis.2020.102269

van Os, J., Delespaul, P., Wigman, J., Myin-Germeys, I., \& Wichers, M. (2013). Beyond DSM and ICD: introducing "precision diagnosis" for psychiatry using momentary assessment technology. World Psychiatry, 12, 113-117. doi:10.1002/wps.20046

von Stumm, S., \& Ackerman, P. L. (2013). Investment and intellect: A review and meta-analysis. Psychological Bulletin, 139, 841-869. doi:10.1037/a0030746

Ware, J. E., \& Sherbourne, C. D. (1992). The MOS 36-item short-form health survey (SF-36): I. Conceptual framework and item selection. Medical Care, 30, 473-483. doi:10.1097/00005650-199206000-00002

Watt, J. D., \& Blanchard, M. J. (1994). Boredom proneness and the need for cognition. Journal of Research in Personality, 28, 44-51. doi:10.1006/jrpe.1994.1005

West, R. F., Toplak, M. E., \& Stanovich, K. E. (2008). Heuristics and biases as measures of critical thinking: Associations with cognitive ability and thinking dispositions. Journal of Educational Psychology, 100, 930-941. doi:10.1037/a0012842

Widaman, K. F., Ferrer, E., \& Conger, R. D. (2010). Factorial invariance within longitudinal structural equation models: Measuring the same construct across time. Child Development Perspectives, 4, 10-18. doi:10.1111/j.1750-8606.2009.00110.x

Xie, Y., Dervieux, C., \& Riederer, E. (2020). R Markdown Cookbook. Chapman and Hall/CRC. ISBN 9780367563837. URL https://bookdown.org/yihui/rmarkdown-cookbook.

Xie, Y., Allaire, J. J., \& Grolemund, G. (2018). R Markdown: The definitive guide. Chapman and Hall/CRC. ISBN 9781138359338. URL https://bookdown.org/yihui/rmarkdown. 
Zainal, N. H., \& Newman, M. G. (2021a). Larger increase in trait negative affect is associated with greater future cognitive decline and vice versa across 23 years. Depression and Anxiety, 38, 146-160. doi:10.1002/da.23093

Zainal, N. H., \& Newman, M. G. (2019). Relation between cognitive and behavioral strategies and future change in common mental health problems across 18 years. Journal of Abnormal Psychology, 128, 295-304. doi:10.1037/abn0000428

Zainal, N. H., \& Newman, M. G. (in press-a). Increased inflammation predicts 9-year change in major depressive disorder diagnostic status. Journal of Abnormal Psychology. doi:10.1037/abn0000716

Zainal, N. H., \& Newman, M. G. (2018). Worry amplifies theory-of-mind reasoning for negatively valenced social stimuli in generalized anxiety disorder. Journal of Affective Disorders, 227, 824-833. doi:10.1016/j.jad.2017.11.084

Zainal, N. H., \& Newman, M. G. (in press-b). Depression and worry symptoms predict future executive functioning impairment via inflammation. Psychological Medicine, 1-11. doi: $10.1017 / \mathrm{s} 0033291721000398$

Zainal, N. H., \& Newman, M. G. (2021b). Depression and executive functioning bidirectionally impair one another across 9 years: Evidence from within-person latent change and crosslagged models. European Psychiatry, 64, e43. doi:10.1192/j.eurpsy.2021.2217

Zainal, N. H., \& Newman, M. G. (2021c). Within-person increase in pathological worry predicts future depletion of unique executive functioning domains. Psychological Medicine, 51, 1676 - 1686. doi:10.1017/S0033291720000422 
Zainal, N. H., Newman, M. G., \& Hong, R. Y. (2021). Cross-cultural and gender invariance of transdiagnostic processes in the United States and Singapore. Assessment, 28, 485-502. doi:10.1177/1073191119869832

Zhang, Z. (2014). Monte Carlo based statistical power analysis for mediation models: methods and software. Behavior Research Methods, 46, 1184-1198. doi:10.3758/s13428-0130424-0

Zhang, Z., Hamagami, F., Grimm, K. J., \& McArdle, J. J. (2015). Using R package RAMpath for tracing SEM path diagrams and conducting complex longitudinal data analysis. Structural Equation Modeling, 22, 132-147. doi:10.1080/10705511.2014.935257

Zhou, M. (2019). The role of personality traits and need for cognition in active procrastination. Acta Psychologica, 199, 102883. doi:10.1016/j.actpsy.2019.102883 